\title{
Study on Positive Personality Cultivation Practice for Local College Students under Perspective of Positive Psychology
}

\author{
Quanli Dou \\ Henan Institute of Education, Zhengzhou, 450000, China
}

Keywords: Positive psychology; Local colleges; Positive personality; Cultivation

\begin{abstract}
Cultivating positive personality of college students becomes a task of higher education and also an important aspect of improving all-round quality of college students. Meanwhile, college students should own positive personality before entering society to resist external pressure or blow. Besides, it is also the foundation for college students to overcome difficulties. Under guidance of positive psychology, psychological health education of college students has good effects and also has important significance for cultivating positive personality of college students. This paper takes college students as the objects of study and analyzes cultivation of positive personality under the perspective of positive psychology.
\end{abstract}

\section{Introduction}

In American psychology circle, positive psychology becomes a new research direction. The researches on positive psychology are also rapidly conducted globally and gradually form a complete system. Besides, the researches point out that the core of positive psychology is subjective well-being which consists of three parts: positive personality, positive experience and positive social system. China's psychology circle studied positive psychology late, but still many achievements have been gained. According to relevant researches, positive psychology can be constructed through cultivation. Thus, positive psychology theory is introduced in psychological health education of college students. Large quantities of practice show that it is feasible to construct positive personality of college students.

\section{Research background}

To study positive personality cultivation of local college students, 950 local college students in 6 provinces were investigated in the form of questionnaire survey. 950 questionnaires were distributed, including 74 ineffective questionnaires and 876 effective questionnaires. The total effective rate is 92.21\%. Meanwhile, in order to ensure typicality of objects of study, questionnaires were distributed to the students ranging from freshmen to senior students, including 386 freshmen (40.63\%), 291 sophomores (30.63\%), 142 junior students (14.95\%) and 131 senior students (13.79\%). Personality power scale was used to test 950 to judge positive personality of college students. Students conducted self-evaluation through 24 items of positive personality, mainly including creativity, braveness, curiosity, integrity, open mind, toughness, vigor, love of learning, ability to love, insight, social intelligence, fairness, generosity, kindness, the quality of citizens, modesty, modest, self-control, cautiousness, hope, appreciation of beauty, humor, gratitude and spiritual belief. It can be seen from questionnaire survey that, gratitude gains the highest score, followed by generosity and modesty, while creativity gains the lowest score, followed by love of learning. In addition, many problems are discovered through knowing performance of college students, and psychology of college students is reflected. It thus can be seen that it is imperative to construct positive personality of college students. This serves as the starting point of this study. 


\section{Bad psychological performance of local college students}

Through observation and analyzing questionnaire survey and psychological performance of college students, the problems and performance are summarized as follows:

\section{Poor judgment ability}

When college students face a pierce of information, if their judgment and reality cannot reach unification, deviation of conception appears. It can be seen from speech and deportment of college students that they often apply the word "should" and "must". Once they firmly believe a thing, they freeze-frame it and form thinking set. However, when what they think conflicts with reality, their psychology will be hurt. This is one of the factors for most students to be caught in puzzle. Excessive perfectionism is the main expression form. Many factors consist of perfectionism, such as family, individual, consciousness and logic. In particular, logic makes college students generate fastidious, rigorous and sequence psychology. They themselves or family members set too high goals for them. These factors cause college students tend to perfectionists. Moreover, in the face of setbacks, the first response of most college students is that they first deny them and cannot accept failure. Meanwhile, they cannot objectively evaluate them and others and also deny others. Thus, interpersonal relationship of college students is not harmonious. There are many phenomena of cliques and conflicts often occur. Furthermore, they excessively exaggerate setbacks. As long as they encounter small setbacks, they will associate many ideas, and negative mood dominates. Even their life will be endangered.

\section{Emotional fluctuations may easily generate negative mood}

College students are in the last step of youth growth, their mood may be easily influenced by external environment or themselves. Full of passion for life, they may easily generate emotional fluctuation, thus leading to negative mood. To be more specific, this is reflected in the following aspects: emotional instability. Many college students reflect they will be agitated and anxious without any reason sometimes. In case of any blow, they will start to deny themselves, which is especially reflected in examination period. The students depressed due to bad performance in examinations are in the majority. They may generate impulsive mood easily. This is because they almost have no social experience and their control consciousness is weak. When something happens, their mood is too impulsive. Even they will generate body conflict. Meanwhile, in the face of various kinds of pressure, their anti-pressure ability is very poor. Dysphoria and depression will occur. Influenced by pessimistic mood, they may even commit suicide.

\section{Weak willpower}

Weak willpower is a ubiquitous phenomenon for contemporary college students. Every college student once had ideals, but most of them have deviated from the path to their ideals. Very few have persisted in their ideals. When encountering setbacks, most will give up their ideals and have no struggling spirit. Some students even change their ideals continuously and cannot stick to their ideals. Some even forget their original ideals and some have abandoned to establish ideals. This is directly related to general poor willpower of college students. When pursuing ideals, once they encounter setbacks, they cannot bear them and then give up. College life is also a small society. There is complex interpersonal relationship and severe employment situation. Their psychology will be affected due to even a small setback. They have depressed consciousness without self-control ability. They especially depend on network. The phenomena of neglecting their studies occur commonly.

\section{No learning motivation}

As a student, learning is their primary task. Learning motivation is the key to ensuring learning ability. But, in line with survey, most students have no interest in learning. When they get in trouble in study, they do not want to solve them and also have no autonomous learning ability with low learning enthusiasm. A universal phenomenon in colleges is that very few students learn. Only during examination period, the self-study room is full of students. Even it is hard to seek a seat.

\section{Deficiency in character}

Contemporary people and especially college students advocate individuality. Some students excessively pursue personality. Thus, various bad characters form. Some are too stubborn, distrust 
and jealous and distrust others. Selfishness exists generally. Many are used to buck-passing. Many college students have buck-passing character and care too much about meaningless concept. Besides, they know this is meaningless, but they cannot control. Thus, they accumulate many pains in self-fighting. Hostility character is also an expression of character defect. They wrongly consider many things or people harmful to them, and thus generate hostility psychology. Hence, aggressive behaviors may easily occur. Such character has great dangerousness.

\section{Significance of cultivating positive personality of college students under positive psychology perspective}

Based on the above summary of psychological performance of college students in questionnaire survey, it can be seen that general psychology of college students has certain problems. So, it is imperative to cultivate their positive personality and promote psychological health of college students. Under the perspective of positive psychology, cultivating positive personality of college students has important significance.

\section{Positive psychology cultivation has new ideas under guidance of positive psychology}

Conducting psychological health education in allusion to their psychological features to achieve their sound development is one of important tasks of local college education. Under theoretical guidance of positive psychology, it is necessary to facilitate college students to establish correct values, and cultivate positive personality with positive ways to solve their psychological problems. Under theoretical guidance of positive psychology, psychological education of colleges starts to change ideology and ways, play the role of expanding contents, make students re-establish values, excavate their psychological factors, make them positively face life and study and promote their mental health development.

Cultivating positive personality of college students is an important approach of integrated development of college students

Under theoretical guidance of positive psychology, cultivating positive personality of college students includes two aspects. It is not just required to cultivate individual positive personality and collective positive personality. This is suitable for the latest ideology in psychological health education. Cultivation of positive personality attaches importance to experiencing subjective well-being. Positive methods are applied to get rid of students' negative psychology and excavate their inner positive factors so that they can positively face study. When getting into trouble in study, they can positively face and solve difficulties. Meanwhile, positive personality is applied in life. In the face of setbacks, students have courage to solve them effectively, instead of depression. It is required to avoid negative emotion influence and promote integrated development of college students.

\section{Positive personality cultivation strategies of local college students under positive psychology perspective}

Under guidance of positive psychology, local universities should have correct strategies during cultivating students' positive personality so as to ensure the optimal effects and do psychological health education well.

To cultivate positive personality of college students through positive emotion experience

Positive emotion experience as an important content of positive psychology can motivate mood of students' behavior tendency. In other words, it makes students affirm their past, full of confidence in present and future and experience sense of happiness anytime. The specific content is to lay emphasis on cultivating subjective well-being of college students, i.e. cultivate them to feel happiness in life, actively excavate happiness and seek real significance of life. Besides, students are trained to carry out self-adjustment of mode. When students are faced with environmental changes or influenced by various factors, they can deal with various situations with positive mood and faced all difficulties and setbacks with positive attitude. The content also includes enhancing students' cognition, making 
them correctly judge all kinds of information in society on the basis of cognitive bias, distinguishing information and guiding practice with correct values.

\section{To pay attention to cultivating positive personality trait}

Personality power cultivation is the cultivation core of positive personality. It excavates positive mentality and personality power of college students, promotes construction of their positive thinking mode and cultivates positive personality trait. It is required to improve positive mentality of college students to a relative level to resist passive mentality, make them face setbacks in life and study with positive mentality, instead of being influenced by negative mood, form thinking mode, and make them actively form positive personality. Cultivating students' positive personality should start from the above 24 aspects, especially their creativity and learning motivation. Construction of positive values is also the key to cultivating students' positive personality. In this way, students can learn and live with correct values. Positive personality contents can be publicized at the broadcasting station or bulletin board. Positive cases can serve as practical cases of health education for teaching so as to guide students to form positive values. College should pay attention to education of love. Meanwhile, students should learn to be grateful and express love so that they can eyepiece sense of happiness.

\section{To construct social cultivation system of positive personality}

Except college education, social guidance plays a great role in constructing positive personality of college students and creating positive living and learning environment for college students. The college, family, society and individual should make joint efforts to promote formation of positive personality and health psychology. Cultivation system can design a cultivation manual to enhance formation of positive personality of college students with emotion as guidance. Moreover, the system should contain relevant consultation module. If students encounter problems, they can directly consult the system to solve doubts and eliminate their negative emotion. Colleges should aim at student service and regard formation of positive personality as the main objective to assist local colleges to carry out psychological health education of college students and promote their comprehensive development.

\section{Conclusions}

Under the perspective of positive psychology, cultivating positive personality of college students is an important content of psychological health education of college students. In allusion to psychological performance of college students in colleges, it can be seen that certain problems exist in college student psychology. They may be especially influenced by negative mood. So, it is imperative to cultivate students' positive personality. This not just has important significance for psychological health education and plays an important role for students' comprehensive development.

\section{Acknowledgments}

This paper is a part of Henan philosophy and social science research project and study on positive personality cultivation practice for local college students project No.: 2014BJY2786.

\section{References}

[1] Xu Jianguo, Li Ping, Development of outward training course of higher vocational colleges with positive personality as value orientation. Heilongjiang Researches on Higher Education, 2012,30(2):99-101

[2] Xiang Yaguang, Wei Hongyun, Shaping positive personality of junior school students under perspective of positive psychology. Primary \& Secondary Schooling Abroad, 2014(1):41-45

[3] Yu Qian, Liu Deyu, Countermeasures to cultivate positive personality of college students under psychological capital perspective. Journal of Lanzhou Jiaotong University, 2013,32(2):148-151 
[4] Zhang Ci, Liu Xiaofeng, Exploraiton of shaping students' positive personality under positive psychology perspective. Journal of Nanchang College of Education, 2013(4):131

[5] Bai Yan, Study on psychological health education of college students under positive psychology perspective. Beijing University of Chemical Technology, 2013 